\title{
Self care in diabetes: a study amongst diabetics in an urban community
}

\author{
Arvind S. Kushwaha ${ }^{1}$, Supriya Kumari ${ }^{2}$, Neha Kushwaha ${ }^{3}$
}

\author{
${ }^{1}$ Station Health Organisation Kirkee, Pune-20, Maharashtra, India \\ ${ }^{2}$ Armed Forces Medical College, Pune-40, Maharashtra, India \\ ${ }^{3}$ Davao Medical School Foundation, Davao, Philippines
}

Received: 12 November 2015

Accepted: 18 December 2015

\section{*Correspondence:}

Dr. Arvind S. Kushwaha,

E-mail: arvind6077@yahoo.com

Copyright: (C) the author(s), publisher and licensee Medip Academy. This is an open-access article distributed under the terms of the Creative Commons Attribution Non-Commercial License, which permits unrestricted non-commercial use, distribution, and reproduction in any medium, provided the original work is properly cited.

\section{ABSTRACT}

Background: Self care of diabetes is essential for control of disease and improvement of quality of patients' life. The aim of this study was to assess the self care practices amongst diabetics and factors influencing self-care practice of patients.

Methods: This is a descriptive community based cross-sectional study carried out on the 69 known diabetic patients in the urban setting in Pune using a questionnaire including SDSCA (Revised Version). The SDSCA measure is a brief self-report questionnaire of diabetes self-management.

Results: Youngest subject was 32 years and eldest was 83 years (Mean 56.67 years SD 10.67 years). The mean weight and BMI of the subjects was $63.02 \mathrm{~kg}$ (SD $9.74 \mathrm{~kg}$ ) and mean BMI $25.55 \mathrm{~kg} / \mathrm{m} 2$ (SD $4.2 \mathrm{~kg} / \mathrm{m} 2)$. Among the co-morbidities, $43(62.3 \%)$ of the patients were hypertensive, followed by $25(36.2 \%)$ having heart problems. Most of the people (65.2\%) rarely got their blood sugar level tested. $88.4 \%$ people never had an ECG test. $29 \%$ diabetics did not engage in any form of exercise even once a day. Most of the subjects $(58 / 69,86.6 \%)$ were not given any advice by their health care staff on the mode and frequency of having their blood sugar checked.

Conclusions: This study found that despite good adherence to medicine, the diabetics were lacking behind in following other lifestyle modifications like diet, exercise, foot care and regular checking of blood glucose.

Keywords: Diabetes, Self care, SDSCA

\section{INTRODUCTION}

Self care of diabetes is essential for control of disease and improvement of quality of patients' life. Earlier patient education was generally prescriptive (e.g., "Do as I say.") and therapeutic goals were set by health professionals. As the large literature in noncompliance indicates, these models were not effective in diabetes care. ${ }^{1-3}$

There have been different types of tools used to measure self-care among diabetics. ${ }^{4-8}$ SDSCA (Summary of Diabetes Self Care Activities) is probably the most widely used self-report instrument for measuring diabetes self-management in adults. ${ }^{9}$
Convincing evidence shows that when patients carry out their self-care with repeated reinforcement of health education, they can improve blood sugar control. It has also been clearly demonstrated that improving metabolic control of diabetes reduces complications and hospitalizations. ${ }^{10,11}$ Studies have revealed that though diabetics have good adherence to drugs but poor knowledge of complications and poor practices related to blood sugar monitoring and lifestyle modification. ${ }^{12-16}$ The aim of this study was to assess the self care practices amongst diabetics and factors influencing self-care practice of patients. 


\section{METHODS}

This was a descriptive community based cross-sectional study carried out on the known diabetic patients in the urban setting in Pune. Assuming $10 \%$ of people in urban population were diabetics, $7 \%$ desired precision along with $95 \%$ confidence interval and applying finite population correction the minimum sample size was worked out to 69 . The patients were chosen by non probability sampling. The following patients were excluded from the study:

a. Patients with disease duration of less than one year.

b. Patients below 18 years of age (still dependent on parents).

c. Patients above 80 years (as they could have senile forgetfulness dementia, etc.).

d. Patients admitted to the hospital.

e. Those not willing to participate.

A two-part questionnaire was designed in which Section A investigated basic patient history (demographics and disease state), while section B was a SDSCA (Revised Version) questionnaire on diabetes mellitus. The SDSCA measure is a brief self-report questionnaire of diabetes self-management that includes items assessing the following aspects of the diabetes regimen: general diet, specific diet, exercise, blood-glucose testing, foot care, and smoking.

\section{RESULTS}

The mean weight of the subjects was $63.02 \mathrm{~kg}$ with standard deviation of $9.74 \mathrm{~kg}$. The weight ranged from 40 $\mathrm{kg}$ to $85 \mathrm{~kg}$. The mean BMI of the study population was $25.55 \mathrm{~kg} / \mathrm{m}^{2}$ with standard deviation of $4.2 \mathrm{~kg} / \mathrm{m}^{2}$. In the survey, it was found that the age of the subjects ranged from 32 years to 83 years; the mean age being 56.67 years with standard deviation of 10.67 years. Only $8.7 \%$ had type 1 diabetes as compared to $17.4 \%$ having type 2 diabetes, while $73.9 \%$ of the patients did not know their diabetes type. In nearly half $(53.6 \%)$ of the patients the duration of the disease was less than five years. Majority $(58 \%)$ of the study population had no family history of diabetes. History of mother being diabetic was most common $(20.3 \%)$ with 7 people $(10.1 \%)$ having more than one family member affected with diabetes. Among the co-morbidities, $43(62.3 \%)$ of the patients were hypertensive, followed by $25(36.2 \%)$ having heart problems. Only $21.7 \%$ carried sugar with them in any form. $82.2 \%$ did go to a doctor for routine checkup. But out of them three fourth $(76.8 \%)$ visited the doctor less than once a year. Most of the people $(65.2 \%)$ rarely got their blood sugar level tested. $88.4 \%$ people never had an ECG test. (Table 1) The majority $(62.3 \%)$ of the subjects were female (Figure 1).
Table 1: Distribution of the study population according to various characteristics.

\begin{tabular}{|c|c|c|}
\hline Characteristic & Frequency & $\%$ \\
\hline \multicolumn{3}{|l|}{ Age Class (Years) } \\
\hline$\leq 40$ & 6 & 8.7 \\
\hline $41-60$ & 37 & 53.6 \\
\hline $61-80$ & 25 & 36.2 \\
\hline$\geq 81$ & 1 & 1.4 \\
\hline \multicolumn{3}{|l|}{ Sex } \\
\hline Male & 26 & 37.7 \\
\hline Female & 43 & 62.3 \\
\hline \multicolumn{3}{|l|}{ Education } \\
\hline Graduate $\&$ above & 11 & 15.9 \\
\hline 8-12 years of schooling & 39 & 56.5 \\
\hline$<8$ years of schooling & 19 & 27.5 \\
\hline \multicolumn{3}{|l|}{$\begin{array}{l}\text { Knowledge about type of } \\
\text { diabetes }\end{array}$} \\
\hline Diabetes mellitus Type 1 & 6 & 8.7 \\
\hline Diabetes mellitus Type 2 & 12 & 17.4 \\
\hline Do not know & 51 & 73.9 \\
\hline \multicolumn{3}{|l|}{$\begin{array}{l}\text { Family History of } \\
\text { Diabetes }\end{array}$} \\
\hline No family history & 40 & 58.0 \\
\hline Father & 12 & 17.4 \\
\hline Mother & 14 & 20.3 \\
\hline Sibling & 9 & 13.0 \\
\hline \multicolumn{3}{|l|}{$\begin{array}{l}\text { Duration of Diabetes } \\
\text { (years) }\end{array}$} \\
\hline$\leq 5$ & 37 & 53.6 \\
\hline $6-15$ & 23 & 33.4 \\
\hline$>15$ & 9 & 13.0 \\
\hline \multicolumn{3}{|l|}{ Associated Co-morbidity } \\
\hline No co morbidity & 7 & 10.1 \\
\hline Hypertension & 43 & 62.3 \\
\hline Coronary Heart Disease & 25 & 36.2 \\
\hline Obesity & 22 & 31.9 \\
\hline Others & 6 & 8.6 \\
\hline
\end{tabular}

\section{Diabetes self care activities undertaken by the study population}

It showed that three fourth $(75.4 \%)$ of the patients adhered to a diet plan for at least five days a week with more than one third $(34.8 \%)$ following it every day. The specific diet response showed that the majority $(86.8 \%)$ followed specific diet plan two to four times a week. 35\% of respondents successfully restricted their calorie intake. $29 \%$ diabetics did not engage in any form of exercise even once a day. Only $61 \%$ achieved the level of exercise recommended to them. Most $(69.5 \%)$ of the subjects had not got their sugar tested even once in previous one week. Monitoring blood sugar levels was more common among those belonging to the higher socioeconomic status than those from the lower socioeconomic status. More than half subjects $(56.5 \%)$ did not take care of their foot even 
once. One third (33.3\%) of the subjects though performed this activity for more than four days a week (Table 2).

\section{Lifestyle recommendations by the $\mathrm{HCWs}$}

Most of the subjects were advised by their health care personnel to follow a low-fat eating plan (69.6\%) and to reduce the number of calories to lose weight (53.6\%). Only $7.2 \%$ were advised on eating lots of fruits and vegetables or were given no advice. Around three fourth $(72.5 \%)$ subjects were given more than one dietary advice (Figure 2).

Table 2: Response to questions related to their Summary of Diabetes Self Care Activities (SDSCA).

\begin{tabular}{|c|c|c|c|c|c|c|c|c|c|}
\hline \multirow[t]{2}{*}{$\begin{array}{l}\text { Item of } \\
\text { Questionnaire }\end{array}$} & \multicolumn{8}{|c|}{ Number of days in a week } & \multirow[b]{3}{*}{$\begin{array}{l}\text { Total } \\
\text { respondents }\end{array}$} \\
\hline & 0 & 1 & 2 & 3 & 4 & 5 & 6 & 7 & \\
\hline & \multicolumn{8}{|c|}{ Frequency of subjects according to response to number of days } & \\
\hline $\begin{array}{l}\text { General diet } \\
\text { response }\end{array}$ & 4 & 0 & 0 & 4 & 9 & 14 & 14 & 29 & \multirow{6}{*}{69} \\
\hline $\begin{array}{l}\text { Specific diet } \\
\text { response }\end{array}$ & 1 & 1 & 15 & 28 & 7 & 5 & 0 & 2 & \\
\hline $\begin{array}{l}\text { Exercise in } \\
\text { previous week } \\
\text { response }\end{array}$ & 20 & 1 & 1 & 2 & 6 & 1 & 5 & 33 & \\
\hline $\begin{array}{l}\text { Blood sugar } \\
\text { testing } \\
\text { response }\end{array}$ & 48 & 17 & 0 & 2 & 0 & 0 & 0 & 2 & \\
\hline $\begin{array}{l}\text { Mean foot care } \\
\text { response }\end{array}$ & 39 & 1 & 3 & 5 & 9 & 3 & 2 & 7 & \\
\hline $\begin{array}{l}\text { Regular } \\
\text { Medication } \\
\text { response }\end{array}$ & 1 & 0 & 0 & 0 & 0 & 4 & 11 & 53 & \\
\hline
\end{tabular}

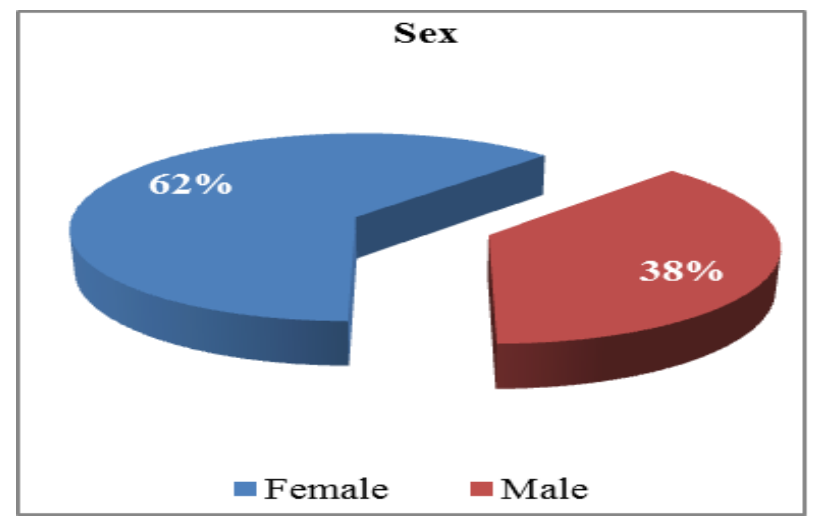

Figure 1: Distribution of the study population according to gender.

Three fourth of the subjects were advised by their health care staff to get a low level exercise on a daily basis. While $11.6 \%$ subjects were not given any advice, $14.5 \%$ subjects were given multiple advises on exercise. (Table 3) Most of the subjects $(58 / 69,86.6 \%)$ were not given any advice by their health care staff on the mode and frequency of having their blood sugar checked (Figure 3).
Table 3: Self care recommendation by health care provider: exercise response in the study population.

\begin{tabular}{|lll|}
\hline $\begin{array}{l}\text { Your health care team has } \\
\text { advised to }\end{array}$ & Frequency & Percent \\
\hline $\begin{array}{l}\text { Get low level exercise on a } \\
\text { daily basis }\end{array}$ & 52 & 75.4 \\
\hline $\begin{array}{l}\text { Exercise continuously for at } \\
\text { least 20 minutes at least 3 } \\
\text { times a week }\end{array}$ & 3 & 4.3 \\
\hline $\begin{array}{l}\text { Fit exercise into your daily } \\
\text { routine }\end{array}$ & 11 & 15.9 \\
\hline $\begin{array}{l}\text { Engage in a specific amount, } \\
\text { type, duration and level of } \\
\text { exercise }\end{array}$ & 4 & 5.8 \\
\hline Other (specify) & 0 & 0.0 \\
\hline $\begin{array}{l}\text { I have not been given any } \\
\text { advice about exercise }\end{array}$ & 8 & 11.6 \\
\hline More than one & 10 & 14.5 \\
\hline Total & 69 & 100.0 \\
\hline
\end{tabular}




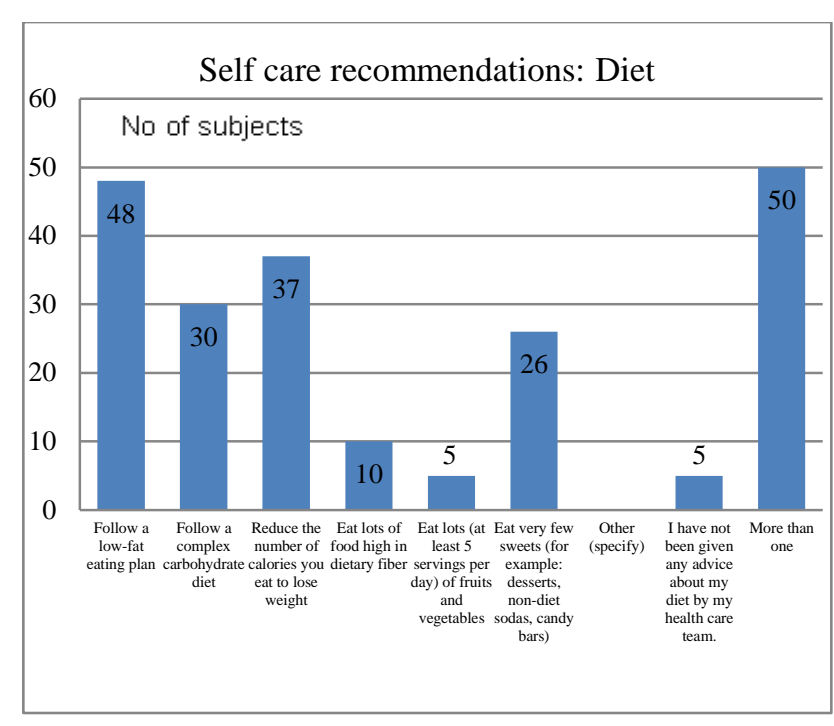

Figure 2: Self care recommendation by health care provider: diet response in the study population.

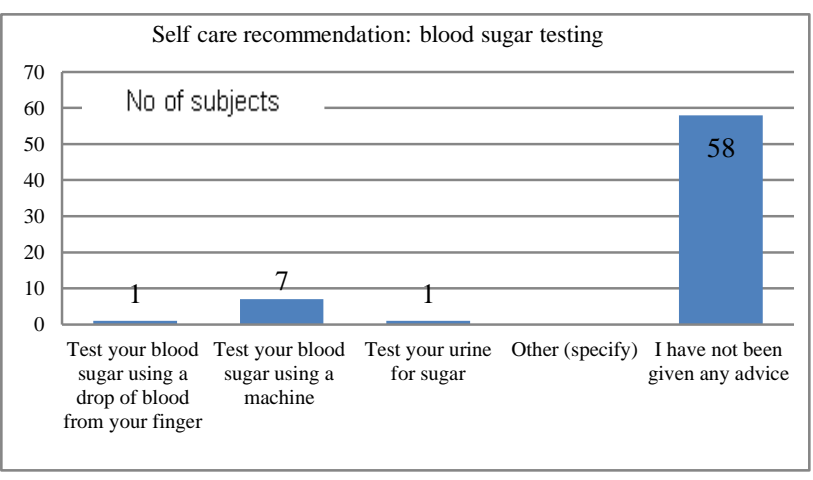

Figure 3: Self care recommendation by Health Care Provider- Blood sugar testing response.

\section{Self care practice}

Three fourth $(76.8 \%)$ of the subjects took their recommended medication every day in the previous week and all but one $(98.6 \%)$ took it regularly for five days or more. Most of the subjects $(65.6 \%)$ took care of their feet for three to five days in the previous week. The score was calculated as the mean of number of days the subjects washed their feet, soak their feet and dry between the toes after washing in the previous seven days. The smoking forms an important risk factor along with co-existing diabetes to lead to complications of diabetes and target organ damage. The smoking status was assessed in terms of current status and doctors counselling on cessation of smoking. Only one third of the subjects (33.3\%) were asked about their smoking status during their last visit to the doctor.

\section{DISCUSSION}

The chronicity of diabetes along with its associated complications and changeability in health status and discomfort level often makes the patients feel that they have lost control over their lives. As people surrender themselves to the expertise of the doctors this sense is exacerbated. Therefore the principle of self care was introduced, which aimed to return this control to the individual, after empowering him with the knowledge about the disease and its management. Its promotion was also motivated by cost-containment for the patient and increasing the autonomy for control over the disease and its complications. Patients must be able to set targets and every day make choices that are equally effective and suit their lifestyles, to manage diabetes successfully.

Therefore this study was conducted with the aim of understanding the practice of self care in diabetics in an urban setting. Diabetes type 2 was more $(17.4 \%)$ in the subjects as compared to diabetes type $1(8.7 \%)$. Most $(73.9 \%)$ of the subjects, though did not know their diabetes type. In nearly half $(53.6 \%)$ of the patients the duration of the disease was less than five years.

Half of the subjects $(49.3 \%)$ had more than one co morbidity. Nearly three fifth subjects (62.3\%) were hypertensive while one third $(36.2 \%)$ had associated heart problems. Though most of the subjects $(82.2 \%)$ did go to a doctor for routine check up but out of them, three fourth $(76.8 \%)$ visited the doctor less than once a year. Two third of the subjects $(69.5 \%)$ had not tested their blood sugar even once in previous one week while $65.2 \%$ subjects rarely got their blood sugar level tested. A study done by Norris SL et al to evaluate the efficacy of selfmanagement education on glycemic control in adults with type 2 diabetes, found that it improved glycemic control at immediate follow-up but the benefit declined 3 months thereafter. ${ }^{10}$ This might suggest the difference in following self care practices as learned behaviours change over time.

A descriptive study done in Brazil to find the knowledge about diabetes mellitus, among the patients and high lighten the importance of self care in subjects with average age of 53.3 years and SD of 13 years with the average duration of disease 2.9 years; found that just over one fourth $(28.6 \%)$ of the subjects correctly knew what was diabetes and its complications, which was much lower $(52.2 \%)$ than the findings in this study. Nearly two third subjects (64\%) had been hospitalized due to an acute or chronic complication, which was comparable $(56.5 \%)$ to this study. The study concluded that little knowledge about the disease was affecting the self care practices thus predisposing the patients towards complications. ${ }^{12}$ This implies that the awareness level about the disease in this study was better may be due to the high literacy rate.

Doctors had provided dietary advice in majority of the subjects $(98.6 \%)$ instead of the dietician $(85.5 \%)$. Studies have shown that most of the diabetes education is conducted by nurses and health educators and the communication style of the health care provider may influence patients' adherence. ${ }^{5}$ 
In this study most of the subjects $(86.6 \%)$ were not given any advice by their health care staff on the mode and frequency of having their blood sugar checked. In a study done in primary and secondary care settings across Scotland it was found that self-monitoring decreased over time in the subjects due to health professionals' inadequate interest in meter readings and lack of education about the appropriate response to readings; indicating that self-monitoring was not worth continuing. ${ }^{16}$

More than half $(56.5 \%)$ of the subjects did not have any addictions while one third $(43.4 \%)$ consumed tobacco. Of these only one third of the subjects $(33.3 \%)$ were asked about their smoking status during their last visit to the doctor while $2.8 \%$ were counselled to stop smoking. Three fourth subjects were advised by their health care staff to get a low level exercise on a daily basis. A three year follow-up multicentre randomized controlled trial done at thirteen primary care units of United Kingdom to measure the benefits of a single education and selfmanagement structured programme of six hours for people with newly diagnosed type 2 diabetes mellitus showed no difference in biomedical $(\mathrm{HbA}(1 \mathrm{c})$, blood pressure, weight, blood lipid levels) or lifestyle outcomes (smoking status, physical activity, drug use) at three years although there were constant improvements in some illness beliefs. It emphasized the importance of repeated health education required for the patients to keep them motivated for self care and increase the compliance of drugs. ${ }^{11}$

In this study around half (47.8\%) of the subjects undertook physical activity for at least 30 minutes in the past week while $61 \%$ subjects did optimum level of exercise. However $29 \%$ of the subjects did not engage in any such exercise even once a day. Though one third $(33.3 \%)$ of the subjects took care of their foot more than four days a week but more than half $(56.5 \%)$ of the subjects did not even do it once a week.

Three fourth (76.8\%) of the subjects took their recommended medication every day in the previous week. Adherence to oral hypoglycaemic agents (86.9\%) was more than that of insulin (33.3\%). Three fourth $(75.4 \%)$ of the patients adhered to a diet plan for at least five days a week with more than one third (34.8\%) following it every day. Only one third (35\%) of the subjects could successfully restricted their calorie intake in this study.

But the self are practise is more prevalent in this study as compared to a cross-sectional survey conducted in an urban community in southern India using the same questionnaire (Summary Diabetes Self-Care Activities SDSCA) to estimate the existing self-care behaviours among adult patients with type 2 diabetes. The study found that good dietary behaviour was present in $29 \%$, good exercise behaviour in $19.5 \%$, regular blood sugar monitoring in $70 \%$ and drug adherence in $79.8 \%$ of the subjects. $^{13}$

Likewise in a hospital based cross sectional study conducted among type 2 diabetics attending diabetes clinic comprising of the age group of 41 to 50 years with half of them having duration of disease between 1 to 5 years and $64 \%$ belonged to lower class; found that almost two third respondents were aware of importance of exercise, diet control and drug compliance. ${ }^{15}$ Similar findings on the awareness and compliance have been seen in other studies done in India. ${ }^{17,18}$ A study in a large mailed survey had also found that individuals most regularly followed their prescribed medication regimen and least regularly followed recommendations for lifestyle changes of diet and exercise. ${ }^{14}$

\section{CONCLUSION}

This study found that the self care practises followed by the subjects were variable and depended on the specific category; that is, while majority of the subjects were having drug compliance but significantly less number had control over their lifestyle (diet, exercise and foot care). $34.8 \%$ of the subjects adhered to a diet plan, $61 \%$ did optimum level of exercise, and $65.6 \%$ took care of their feet most days in the previous week whereas $76.8 \%$ had drug compliance. The advice given by the doctor was also found inadequate. Only one third of the subjects $(33.3 \%)$ were asked about their smoking status while only $2.8 \%$ were counseled to stop smoking. Most of the subjects $(86.6 \%)$ were not given any advice on the mode and frequency of having their blood sugar checked. Doctors had provided dietary advice in majority of the subjects $(98.6 \%)$ instead of the dietician $(85.5 \%)$. The doctors though fared well in advising the subjects on getting a low level exercise on a daily basis.

\section{Recommendations}

This study found that despite good adherence to medicine, the diabetics were lacking behind in following other lifestyle modifications like diet, exercise, foot care and regular checking of blood glucose.

Funding: Indian Council of Medical Research Short Term Studentship Program reference ID Number: 201200897

Conflict of interest: None declared

Ethical approval: The study was approved by the Institutional Ethics Committee

\section{REFERENCES}

1. Funnell MM, Anderson RM. The problem with compliance in diabetes. JAMA. 2000;284:1709.

2. Anderson RM, Funnell MM. Compliance and adherence are dysfunctional concepts in diabetes care. Diabetes Educ. 2000;26:597-604. 
3. Glasgow RE, Anderson RM: In diabetes care, moving from compliance to adherence isnot enough. Diabetes Care. 1999;22:2090-1.

4. Brownlee-Duffeck M, Peterson L, Simonds JF, Goldstein D, Kilo C. The role of health beliefs in the regimen adherence and metabolic control of adolescents and adults with diabetes mellitus. J Consult Clinical Psychol. 1987;55:139-44.

5. Cerkoney KA, Hart LK. The relationship between the health belief model and compliance of persons with diabetes mellitus. Diabetes Care. 1980;3:594-8.

6. Orme CM, Binik YM. Consistency of adherence across regimen demands. Health Psychol. 1989;8:2743.

7. Marquis K, Ware J. Measures of Diabetic Patient Knowledge, Attitudes and Behavior Regarding SelfCare. 1979 Santa Monica, CA, Rand Corporation.

8. Johnson SB, Silverstein J, Rosenbloom A, Carter R, Cunningham W. Assessing daily management of childhood diabetes. Health Psychol. 1986;5:545-64.

9. Toobert DJ, Hampson SE, Glasgow RE. The summary of diabetes self-care activities measure: results from 7 studies and a revised scale. Diabetes Care. 2000;23(7):943-50.

10. Norris SL, Lau J, Smith SJ, Schmid CH, Engelgau MM. Self-management education for adults with type 2 diabetes: a meta-analysis of the effect on glycemic control. Diabetes Care. 2002;25(7):115971.

11. Khunti K, Gray LJ, Skinner T, Carey ME, Realf K, Dallosso H, Fisher H, Campbell M, Heller S, Davies MJ. Effectiveness of a diabetes education and self management programme (DESMOND) for people with newly diagnosed type 2 diabetes mellitus: three year follow-up of a cluster randomised controlled trial in primary care. BMJ. 2012 26;344:e2333.

12. Pace AE, Ochoa-Vigo K, Caliri MH, Fernandes AP. Knowledge on diabetes mellitus in the self care process. Rev Lat Am Enfermagem. 2006;14(5):72834.

13. Gopichandran V, Lyndon S, Angel MK, Manayalil BP, Blessy KR, Alex RG, et al. Diabetes self-care activities: a community-based survey in urban southern India. Natl Med J India. 2012;25(1):14-7.

14. Ruggiero L, Glasgow R, Dryfoos JM, Rossi JS, Prochaska JO, Orleans CT, et al. Diabetes selfmanagement. Self-reported recommendations and patterns in a large population. Diabetes Care. 1997;20(4):568-76.

15. Padma K, Bele SD, Bodhare TN, Valsangkar S. Evaluation of knowledge and self care practices in diabetic patients and their role in disease management. Natl J Com Med. 2012;3(1):3-6.

16. Peel E, Douglas M, Lawton J. Self monitoring of blood glucose in type 2 diabetes: longitudinal qualitative study of patients' perspectives. BMJ. 2007;335(7618):493.

17. Shah VN, Kamdar PK, Shah N. Assessing the knowledge, attitudes and practice of type 2 diabetes among patients of Saurashtra region, Gujarat. Int J Diabetes Dev Ctries. 2009;29:118-22.

18. Priyanka CK, Angadi MM. Hospital-based KAP study on Diabetes in Bijapur, Karnataka. Indian Journal of Medical Specialties. 2010;1:80-3.

Cite this article as: Kushwaha AS, Kumari S, Kushwaha N. Self care in diabetes: a study amongst diabetics in an urban community. Int J Community Med Public Health. 2016;3:293-8. 